Article

\title{
Synthesis of Ultramarine from Reservoir Silts
}

\author{
Yin-Hsiu Hsiao, Yun-Hwei Shen and Dah-Tong Ray * \\ Department of Resources Engineering, National Cheng Kung University, 1 Da-Hsueh Road, \\ Tainan 70101, Taiwan R.O.C.; N48981064@mail.ncku.edu.tw (Y.-H.H.); yhshen@mail.ncku.edu.tw (Y.-H.S.) \\ * Correspondence: raydon@mail.ncku.edu.tw; Tel.: +886-6-2757575 (ext. 62831)
}

Academic Editor: Radostina G. Atanassova

Received: 27 March 2017; Accepted: 4 May 2017; Published: 7 May 2017

\begin{abstract}
Ultramarine blue was synthesized by using reservoir silts as a major raw material to replace traditional kaolin clay. The reservoir silts were pretreated to collect the fines, in which the main mineral composition is illite clay. The fine part was mixed with sodium carbonate, sulfur, and activated carbon, and calcined at $800^{\circ} \mathrm{C}$ for $8 \mathrm{~h}$. The products were examined by X-ray powder diffraction (XRD) and a scanning electron microscope (SEM) to identify the mineral phases and particle morphology. The color characteristics were measured according to the CIELab system. Brilliant blue ultramarine powders were successfully synthesized with a chroma of 52.4, which is competitive with the commercial ultramarine.
\end{abstract}

Keywords: reservoir silts; ultramarine; synthesis

\section{Introduction}

The annual sedimentation rate of the world's reservoirs averages about $1 \%$, but it is much higher in Asia [1,2]. Due to climatic, geographic and geologic situations, the reservoir sedimentation problem is very serious in southern Taiwan, R.O.C. All the streams have steep slopes in their catchment areas. The rainfall intensity and runoff flow are strong during the summer typhoon season. Even worse, major irrigation and city water supply reservoirs are located in Pliocene and Pleistocene shale and mudstone areas. The accumulated sediment volume in these reservoirs accounts for about one third or more of the reservoir designed capacity [3]. To extend the operation life of these reservoirs, desiltation is essential. Reservoir desiltation involves three major processes, namely the removal, deposition and reuse of the silt. The reuse of the silt is the most important one because improper handling of dredged silts will interrupt the removal operation.

The major mineral components of reservoir sediments in southern Taiwan are sand (mostly quartz) and clay (illite and chlorite) [4]. Since the hardness of quartz is greater than that of the clay minerals, these two types of minerals are concentrated in different size ranges, i.e. sand in the coarse-grained range and clay minerals in the fine-grained range. Using sedimentation technique in mineral processing, it is easy to separate out clay minerals. From the point of view of chemical composition, after the removal of quartz, reservoir silts can be regarded as a natural aluminosilicate mineral source.

Ultramarine with its deep vivid blue is a valuable inorganic pigment. Natural ultramarine is derived from grinding lapis lazuli, which is a rock composed of lazurite with small amounts of calcite, pyroxene, etc. Most of today's ultramarine is synthetically produced based upon processes invented by Guimet in 1826 and Gmelin in 1828 [5].

Ultramarine or lazurite has the same crystal structure of sodalite, $\mathrm{Na}_{8}\left[(\mathrm{Al}, \mathrm{Si})_{6} \mathrm{O}_{24}\right] \mathrm{Cl}_{2}$, which is a feldspathoid group mineral with a zeolite structure. In ultramarine, the chloride ions are replaced by the sulfur radical anions $\mathrm{S}_{3}{ }^{-}$and $\mathrm{S}_{2}{ }^{-}$. The chemical formula of ultramarine thus is $\mathrm{M}_{8}\left[(\mathrm{Al}, \mathrm{Si})_{6} \mathrm{O}_{24}\right] \mathrm{X}_{\mathrm{n}}$, where $\mathrm{M}$ is an extra-framework cation, mainly $\mathrm{Na}^{+} ; \mathrm{X}$ is an extra-framework anion, such as $\mathrm{S}_{2}{ }^{-}, \mathrm{S}_{3}{ }^{-}$, 
etc., and n may vary from 2 to 4 [6-9]. The anions and cations balance the charge on the ordered aluminosilicate framework. The close-packed cuboctahedra $\left(\mathrm{Al}_{3} \mathrm{Si}_{3} \mathrm{O}_{12}\right)^{3-}$ called $\beta$ cages organize the sodalite (SOD) structure (Figure 1a) [10].The chromophores of ultramarine are polysulfide radical anions encapsulated inside $\beta$ cages (Figure 1b) [7]. Theoretical maximum insertion of chromophores is one $S_{x}{ }^{-}$per $\beta$ cage $(x=2-4)$. The polysulfide radicals $S_{2}{ }^{-}, S_{3}{ }^{-}$and $S_{4} / S_{4}{ }^{-}$are responsible for the yellow, blue and red colors, respectively [7,10-15]. The cause of color is due to the absorption band at about $400 \mathrm{~nm}\left(\mathrm{~S}_{2}{ }^{-}\right), 600 \mathrm{~nm}\left(\mathrm{~S}_{3}{ }^{-}\right)$and $520 \mathrm{~nm}\left(\mathrm{~S}_{4} / \mathrm{S}_{4}{ }^{-}\right)$, resulted from the transition of electrons among the molecular orbitals of these polysulfide radical anions from ground state to low-lying excited electronic states [13-18].

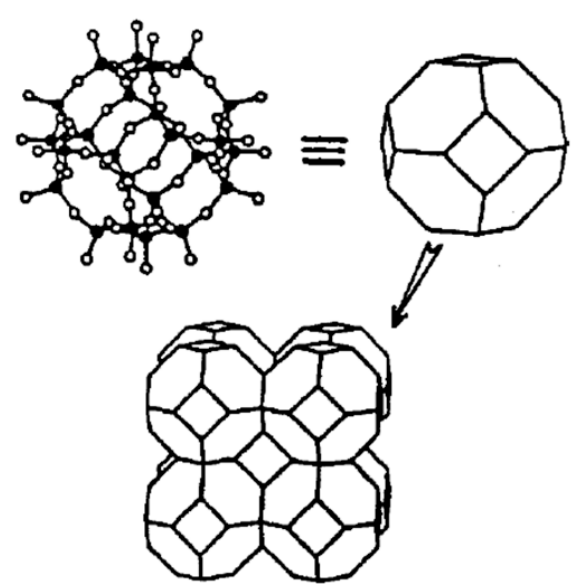

(a)

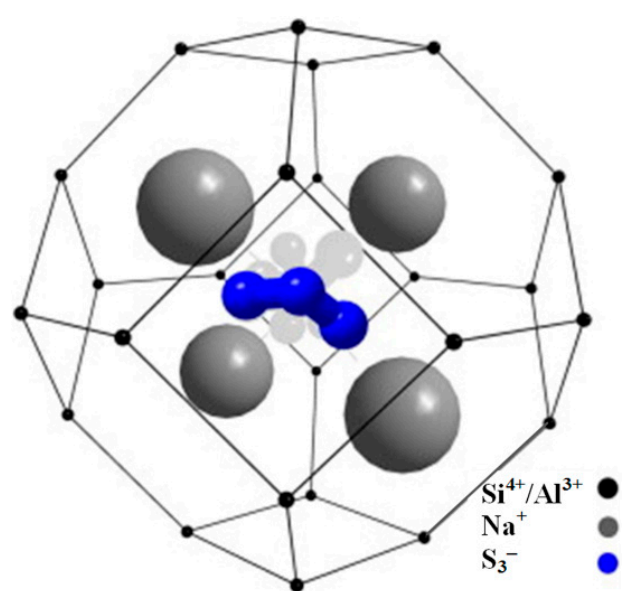

(b)

Figure 1. Schematic illustration of (a) sodalite (SOD) structure composed of $\beta$ cages [10] and (b) blue chromophore $\mathrm{S}_{3}{ }^{-}$encapsulated in $\beta$ cages and surrounded by four sodium cations [7].

The ratio of $\mathrm{Si}$ to $\mathrm{Al}$ determines the amount of chromophores encapsulated inside $\beta$ cages. When fewer $\mathrm{Al}$ ions are present in the framework, the required number of sodium ions is reduced for lattice stabilization, and more sodium ions are free to act as counter-ions for the polysulfide. The polysulfide content can be increased and thereby improve color quality [19,20]. Within limits set by stability considerations, the proportions of the chemical constituents can vary. Some empirical formulas, likeNa ${ }_{6.9} \mathrm{Al}_{5.6} \mathrm{Si}_{6.4} \mathrm{O}_{24} \mathrm{~S}_{4.2}$ [19], are reported.

Traditionally, the raw material used in the synthesis of ultramarine is kaolin clay. The industrial process of ultramarine synthesis involves the dehydration of kaolin at about $550{ }^{\circ} \mathrm{C}$. The dehydrated clay is mixed with sulfur, sodium carbonate and a reducing agent, e.g., coke or active carbon. Heating of the mixture produces a synthesis reaction [21]. In the reaction, the formation of ultramarine blue proceeds in two stages: first a reduction stage followed by an oxidation stage. In the reduction stage, the mixture is heated to about $750{ }^{\circ} \mathrm{C}$, and held at that temperature for a given period of time. The container for the mixture is covered so that a reducing atmosphere can be maintained within it. When the holding time is reached, the temperature starts to descend, and the reaction enters the oxidation stage. The oxidation stage is achieved by either keeping the mixture at about $450{ }^{\circ} \mathrm{C}$ for a fixed time or simply slowing the cooling rate. During this stage, $\mathrm{S}_{2}{ }^{-}$ions are oxidized to $\mathrm{S}_{3}{ }^{-}$ions to produce a vivid blue hue $[20,21]$.

Besides kaolin, other aluminosilicate sources, including pure chemicals, natural or synthetic minerals and wastes have been used. Chemicals, such as sodium silicate and tetramethylammonium hydroxide [22]; silicon tetrachloride and aluminum chloride [8]; silica, diatomaceous earth and sodium aluminate [23]; natural or synthetic minerals, like zeolite A, X, Y [24-26], cancrinite [27], hydroxycancrinite [28]; wastes, such as fly ash [20] and kaolin mine tailings [29], were reported to be technologically feasible. 
In a previous study, the reservoir silts were first treated hydrothermally to transform them to hydroxycancrinite [28]; then the hydroxycancrinite was transformed to ultramarine blue via a solid-state reaction process. In this study, reservoir silts were used directly to synthesize ultramarine. The reaction conditions, such as raw materials ratio, calcination temperature and mineral composition of silts on the product phase and color properties, were investigated.

\section{Experimental}

\subsection{Materials}

The reservoir silt samples were taken from the city water supply of Nan-Hua Reservoir that is located in Tainan County. The silts were screened through a 200 mesh sieve $(75 \mu \mathrm{m})$, to remove the non-mineral constituents, such as humus, etc., and then the material was designated as the "raw" silt. The raw silts were further classified via hydraulic sedimentation to separate out the $<10 \mu \mathrm{m},<5 \mu \mathrm{m}$, and $<2 \mu \mathrm{m}$ parts.

The size distribution of the raw silts is shown in Figure 2. The distribution fits quite well that of the Gates-Gaudin-Schuhmann distribution function with the distribution modulus of 0.77 and $d_{50}$ of $5.7 \mu \mathrm{m}$. From the distribution curve, it can be determined that the $<10 \mu \mathrm{m},<5 \mu \mathrm{m}$ and $<2 \mu \mathrm{m}$ parts account for 62,47 , and $33 \mathrm{wt} \%$ of the raw silts, respectively.

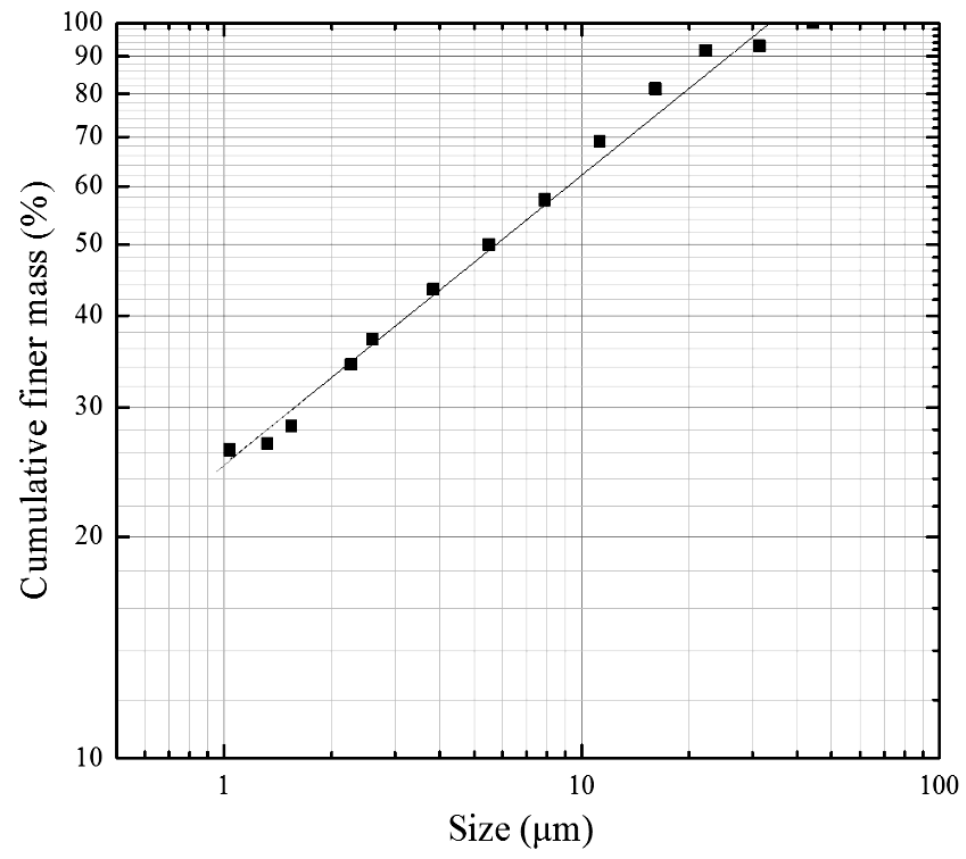

Figure 2. Particle size distribution of raw silts.

The XRD patterns of the raw and classified silt samples are shown in Figure 3. The diffraction peaks show that the minerals comprising the silt are quartz, illite, clinochlore and albite. As the size of the silts is decreased, the peaks of quartz and albite decrease rapidly, whereas those of illite and clinochlore are more prominent. The change in mineral composition shows that size classification can separate quartz and albite, which are unusable in the synthesis reaction, from clay minerals effectively.

The chemical compositions of all silt samples determined by XRF are listed in Table 1 . With the removal of quartz from classified silts, the molar ratio of $\mathrm{Si} / \mathrm{Al}$ decreases from 2.77 to 1.42. 


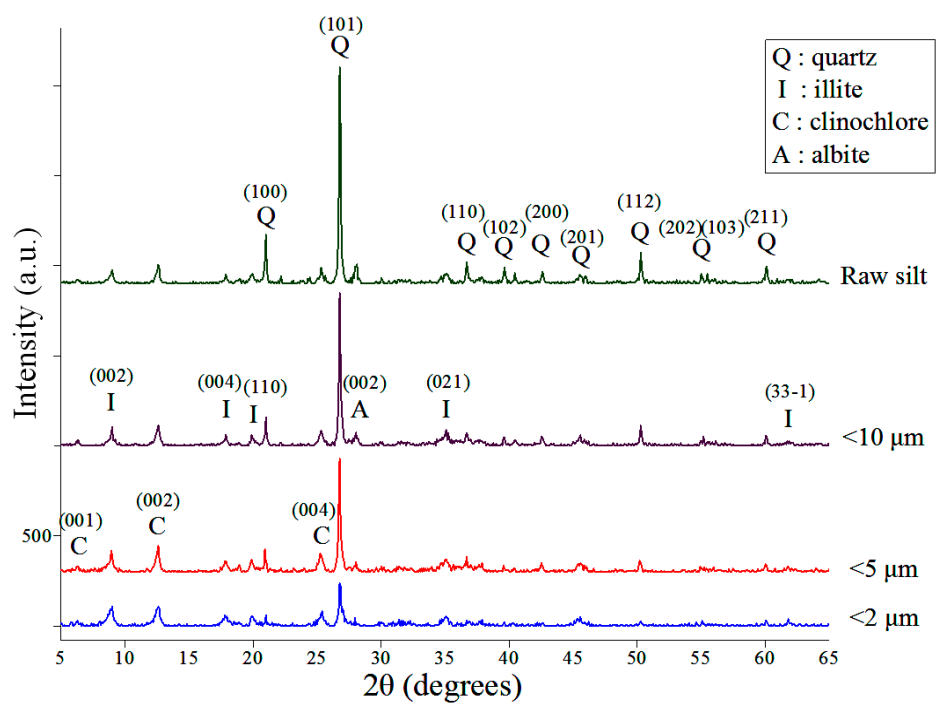

Figure 3. XRD patterns of raw and classified silts.

Table 1. Chemical analysis of raw and classified silts.

\begin{tabular}{ccccc}
\hline Components & Raw & $<\mathbf{1 0} \boldsymbol{\mu m}$ & $<5 \mu \mathbf{m}$ & $<\mathbf{2} \mathbf{m}$ \\
\hline $\mathrm{Na}_{2} \mathrm{O}$ & $\mathrm{a}$ & $\mathrm{a}$ & 0.62 & 1.15 \\
$\mathrm{MgO}$ & 2.03 & 2.23 & 2.48 & 2.75 \\
$\mathrm{~K}_{2} \mathrm{O}$ & 3.33 & 3.93 & 4.33 & 4.81 \\
$\mathrm{CaO}$ & 1.48 & 1.29 & 1.21 & 1.22 \\
$\mathrm{Fe}_{2} \mathrm{O}_{3}$ & 6.11 & 7.34 & 7.97 & 8.29 \\
$\mathrm{Al}_{2} \mathrm{O}_{3}$ & 19.61 & 22.25 & 24.74 & 27.74 \\
$\mathrm{SiO}$ & 63.97 & 60.86 & 56.9 & 51.48 \\
$\mathrm{Si} / \mathrm{Al}$ & 2.77 & 2.32 & 1.95 & 1.58 \\
\hline
\end{tabular}

a: Below the detection limit $0.44 \%$.

The SEM images of the raw and classified silts are shown in Figure 4. It is clear that with decreasing particle sizes, the major mineral images gradually vary from massive, which represents quartz, to sheet-like, which represents clay minerals.
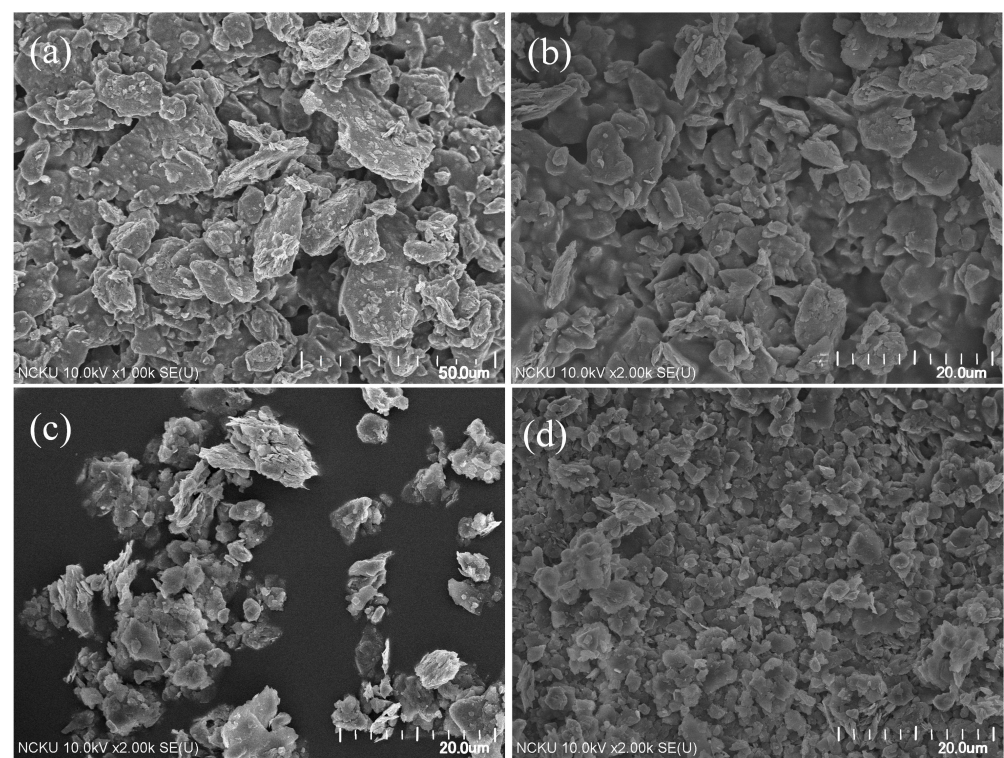

Figure 4. SEM micrographs of (a) raw; (b) $<10 \mu \mathrm{m}$; (c) $<5 \mu \mathrm{m}$ and (d) $<2 \mu \mathrm{m}$ silts. 


\subsection{Procedures}

The silts were fully mixed with sulfur (purified, Katayama Chemical Co. Ltd., Osaka, Japan) and active carbon (100-400 mesh, Sigma-Aldrich Chemie GmbH, Munich, Germany). An aliquot of sodium carbonate (reagent grade, Fisher Scientific, Leicestershire, UK) solution of assigned concentrations was slowly added to the powder and was hand-kneaded to balls and then dried in air. It was reported $[29,30]$ that in the reaction, sulfur and sodium carbonate are reacted as:

$$
3 \mathrm{Na}_{2} \mathrm{CO}_{3}+1.25 \mathrm{~S}_{8} \leftrightarrow 2 \mathrm{Na}_{2} \mathrm{~S}_{4}+\mathrm{Na}_{2} \mathrm{~S}_{2} \mathrm{O}_{3}+3 \mathrm{CO}_{2}
$$

From the $\mathrm{Na}_{2} \mathrm{CO}_{3} / \mathrm{S}_{8}$ molar ratio in the above equation, the $\mathrm{Na}_{2} \mathrm{CO}_{3} / \mathrm{S}_{8}$ weight ratio is approximately equivalent to 1 . This ratio was held constant in this study. The dried balls were placed in an alumina crucible covered with a lid and calcined at 700,800 and $900{ }^{\circ} \mathrm{C}$ for $2,4,8$ and $12 \mathrm{~h}$.

After completion of the reaction, the crucible was allowed to cool down to room temperature in the furnace. The cooling took about $8 \mathrm{~h}$. The reacted balls were mixed with deionized water, stirred thoroughly and filtered several times to remove all dissolved ions. The solids were dried at $120^{\circ} \mathrm{C}$ for $24 \mathrm{~h}$ and for further analyses.

\subsection{Characterization}

The mineral phases of the sediment and products were characterized using an X-ray diffractometer (DX-2600, Fangyuan Co., Dandong, China) with $\mathrm{Cu} \mathrm{K}_{\alpha}(\lambda=1.5418 \AA)$ radiation and a scan rate of $0.04^{\circ} \mathrm{s}$. The chemical compositions were analyzed using an X-ray Fluorescence Analyzer (NEX CG EDXRF elemental analyzer, Rigaku Corp., Tokyo, Japan). The particle size distribution was determined using an Andreasen pipette. The morphology and individual particle sizes were examined using a Hitachi 8000 High-Resolution Scanning Electron Microscope (HRSEM, Hitach Ltd., Ibaraki, Japan). The color characteristics of the synthesized products were measured using a sphere spectrophotometer SP-60 (X-Rite Inc., Grand Rapids, MI, USA) employing the CIELab (Commission Internationale de l'Éclairage) color spaces system. The measurements (Standard Illuminant D65/10 ${ }^{\circ}$ ) performed were chromaticity or color saturation $\left(C^{*}=0\right.$ for grey color, $C^{*}=100$ for pure chromatic components), lightness ( $L^{*}=0$ for a black sample, $L^{*}=100$ for a white sample) and hue $\left(h^{*}=0^{\circ}, 90^{\circ}, 180^{\circ}, 270^{\circ}\right.$ for red, yellow, green and blue colors, respectively).

\section{Results and Discussion}

\subsection{Effects of Calcination Condition}

\subsubsection{Reaction Temperature}

The $<5 \mu \mathrm{m}$ silts were used in these calcination tests. The mass ratio of $\left(\mathrm{Na}_{2} \mathrm{CO}_{3}+\mathrm{S}_{8}\right)$ and active carbon to silt were maintained at 1.5 and 0.2 , respectively. The XRD patterns of the products calcined at 700,800 and $900{ }^{\circ} \mathrm{C}$ for $8 \mathrm{~h}$ are shown in Figure 5. For all reaction temperatures, lazurite was the major phase formed. Nepheline was also formed for temperatures below $800^{\circ} \mathrm{C}$. When reaction temperature reached $900{ }^{\circ} \mathrm{C}$, nepheline disappeared.

The color properties of the products are listed in Table 2. When calcination was performed at $800^{\circ} \mathrm{C}$, the chroma of the product achieved optimum. Both lower or higher than this temperature were deleterious. This could be because that lower temperature does not promote the reaction efficiently, whereas higher temperature accelerates the loss of sulfur chromophores. 


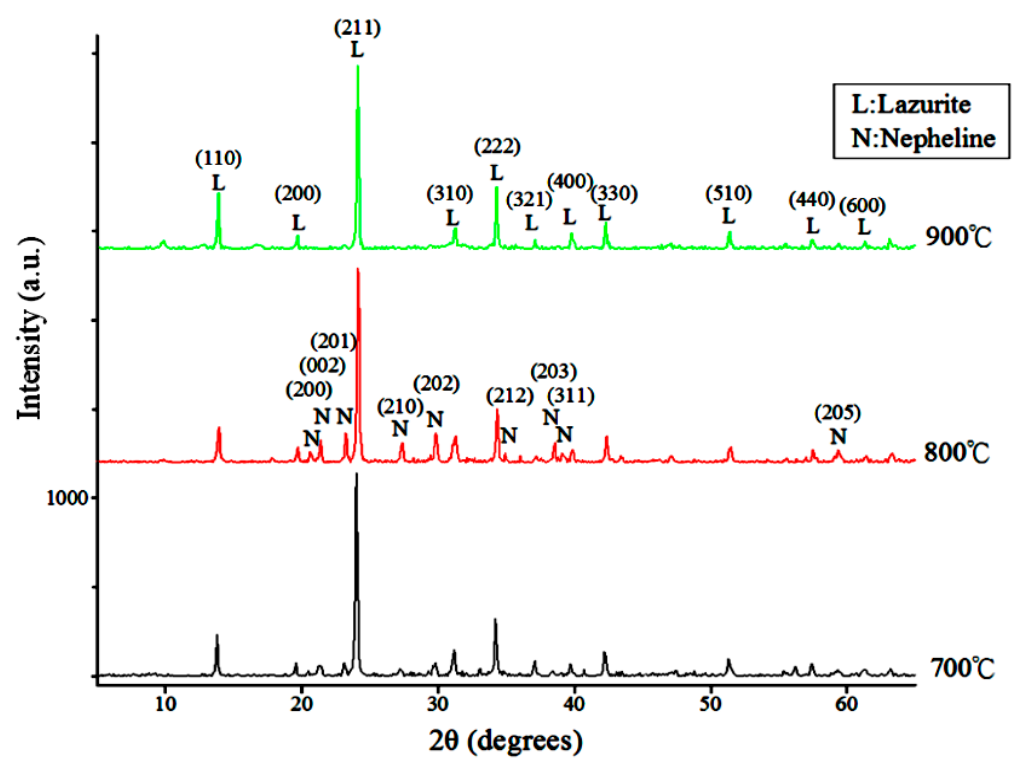

Figure 5. XRD patterns of the products derived from $<5 \mu \mathrm{m}$ silts calcined at 700,800 , and $900{ }^{\circ} \mathrm{C}$ for $8 \mathrm{~h}\left(\left(\mathrm{Na}_{2} \mathrm{CO}_{3}+\mathrm{S}_{8}\right) /\right.$ silts $=1.5, \mathrm{C} /$ silts $\left.=0.2\right)$.

Table 2. Color properties of products derived from $<5 \mu \mathrm{m}$ silts calcined at 700,800 , and $900{ }^{\circ} \mathrm{C}$ for $8 \mathrm{~h}$ $\left(\left(\mathrm{Na}_{2} \mathrm{CO}_{3}+\mathrm{S}_{8}\right) /\right.$ silts $=1.5, \mathrm{C} /$ silts $\left.=0.2\right)$.

\begin{tabular}{ccccc}
\hline Calcination Temperature & $\mathbf{L}^{*}$ & $\mathbf{C}^{*}$ & $\mathbf{h}^{*}$ & Pantone \\
\hline $700{ }^{\circ} \mathrm{C}$ & 36.25 & 40.30 & 266.8 & \\
& & & & \\
$800^{\circ} \mathrm{C}$ & 37.86 & 51.12 & 275.5 & \\
$900{ }^{\circ} \mathrm{C}$ & 38.81 & 28.24 & 244.2 & \\
\hline
\end{tabular}

The results of Figure 5 and Table 2 shows that the color properties are determined by crystal structure as well as the amount of polysulfide radical anions kept in the $\beta$ cage. The latter is more important, as can be seen from the XRD patterns of the $800{ }^{\circ} \mathrm{C}$ product. Although some nepheline is still present, it represents the best color properties.

\subsubsection{Reaction Duration}

Figure 6 shows the XRD patterns of the products calcined at $800{ }^{\circ} \mathrm{C}$ for $2-12 \mathrm{~h}$. After $2 \mathrm{~h}$ of calcination, lazurite formed with a minor amount of nepheline. Lazurite obviously is the stable phase, as it can be seen that all diffraction peaks kept increasing even after $12 \mathrm{~h}$ of calcination. Nepheline on the other hand, seemed to be an intermediate phase, and disappeared gradually as calcination proceeded. The color properties of the products are listed in Table 3. The best chroma was obtained at the reaction time of $8 \mathrm{~h}$. It is obvious for long time calcination that $\mathrm{S}_{3}{ }^{-}$chromophores may vaporize from the clathrate. According to the above results, $800{ }^{\circ} \mathrm{C}$ and $8 \mathrm{~h}$ were used as the calcination conditions for the next test. 


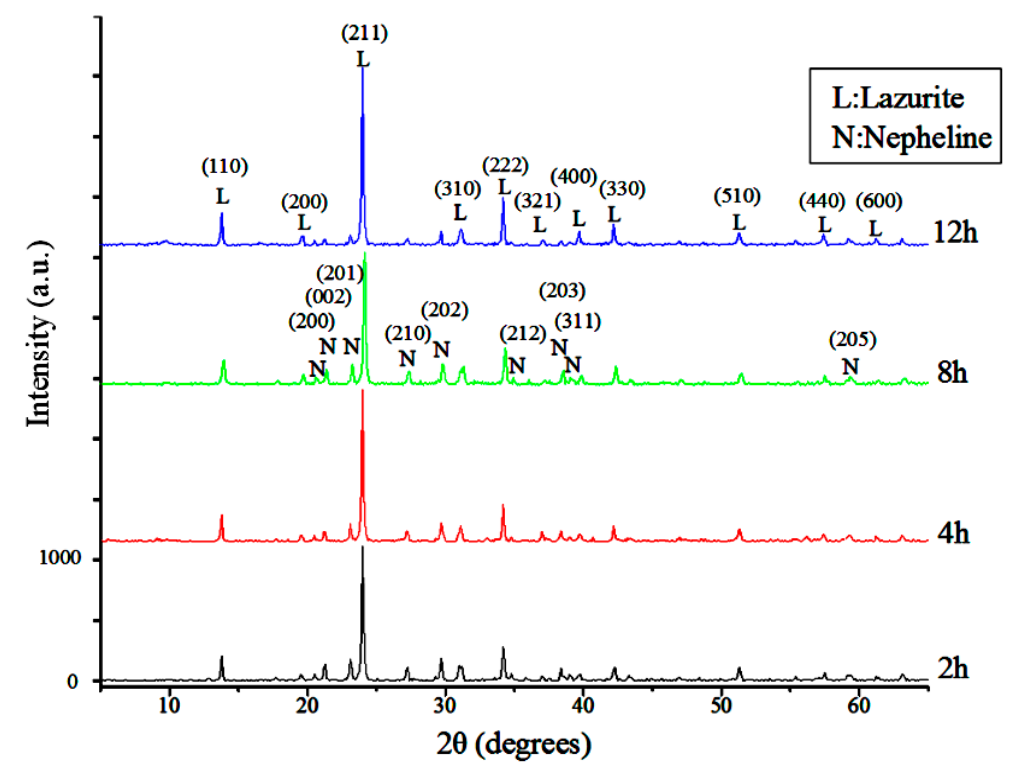

Figure 6. XRD patterns products derived from $<5 \mu \mathrm{m}$ silts calcined at $800{ }^{\circ} \mathrm{C}$ for $2-12 \mathrm{~h}$ $\left(\left(\mathrm{Na}_{2} \mathrm{CO}_{3}+\mathrm{S}_{8}\right) /\right.$ silts $=1.5, \mathrm{C} /$ silts $\left.=0.2\right)$.

Table 3. Color properties of products derived from $<5 \mu \mathrm{m}$ silts calcined at $800{ }^{\circ} \mathrm{C}$ for $2-12 \mathrm{~h}$ $\left(\left(\mathrm{Na}_{2} \mathrm{CO}_{3}+\mathrm{S}_{8}\right) /\right.$ silts $=1.5, \mathrm{C} /$ silts $\left.=0.2\right)$.

\begin{tabular}{ccccc}
\hline Calcination Time & $\mathrm{L}^{*}$ & $\mathrm{C}^{*}$ & $\mathbf{h}^{*}$ & Pantone \\
\hline $2 \mathrm{~h}$ & 41.75 & 37.8 & 258.1 & \\
\hline $4 \mathrm{~h}$ & 42.27 & 36.15 & 256.6 & \\
& & & & \\
$8 \mathrm{~h}$ & 37.86 & 51.12 & 275.5 & \\
$12 \mathrm{~h}$ & 39.78 & 33.08 & 250.8 & \\
\hline
\end{tabular}

\subsection{Effects of Raw Materials Ratio}

\subsection{1. $\left(\mathrm{Na}_{2} \mathrm{CO}_{3}+\mathrm{S}_{8}\right) /$ Silts Ratio}

The $<5 \mu \mathrm{m}$ silts were used in this test. There are two concerns about raw material ratios, one is the weight ratio of $\mathrm{Na}_{2} \mathrm{CO}_{3}+\mathrm{S}_{8}$ to silts (at $\mathrm{Na}_{2} \mathrm{CO}_{3} / \mathrm{S}_{8}=1$ ), the other is the active carbon to silts. The mixtures were heated at $800{ }^{\circ} \mathrm{C}$ for $8 \mathrm{~h}$. The color properties of the products of all tests are summarized in Table 4.

The effect of $\left(\mathrm{Na}_{2} \mathrm{CO}_{3}+\mathrm{S}_{8}\right) /$ silts ratio on the color properties (chroma, lightness and hue) of the products for reactions with active carbon/silts ratio $=0.2$ is shown in Figure 7. With the $\left(\mathrm{Na}_{2} \mathrm{CO}_{3}+\mathrm{S}_{8}\right) /$ silts ratio increased from 1 to $1.5,2$, the chroma increased from 38.9 to 50.2, 53.3, while lightness and hue still remained at the similar levels but much improved to around $30^{\circ}$ and $275^{\circ}$, respectively. For the economical reason, the $\left(\mathrm{Na}_{2} \mathrm{CO}_{3}+\mathrm{S}_{8}\right) /$ silts ratio $=1.5$ was adopted in the later tests. 
Table 4. Color properties of products derived from $<5 \mu \mathrm{m}$ silts at different $\left(\mathrm{Na}_{2} \mathrm{CO}_{3}+\mathrm{S}_{8}\right) /$ silts ratio $\left(800^{\circ} \mathrm{C}, 8 \mathrm{~h}\right)$.

\begin{tabular}{cccccc}
\hline$\left(\mathrm{Na}_{\mathbf{2}} \mathrm{CO}_{3}+\mathbf{S}_{8}\right) /$ Silts & $\mathbf{C} /$ Silts & $\mathbf{L}^{*}$ & $\mathbf{C}^{*}$ & $\mathbf{h}^{*}$ & Pantone \\
\hline 1 & 0.2 & 28.92 & 38.89 & 270.3 & \\
1.5 & 0.2 & 31.23 & 50.23 & 275.7 & \\
2 & & & & & \\
\hline
\end{tabular}

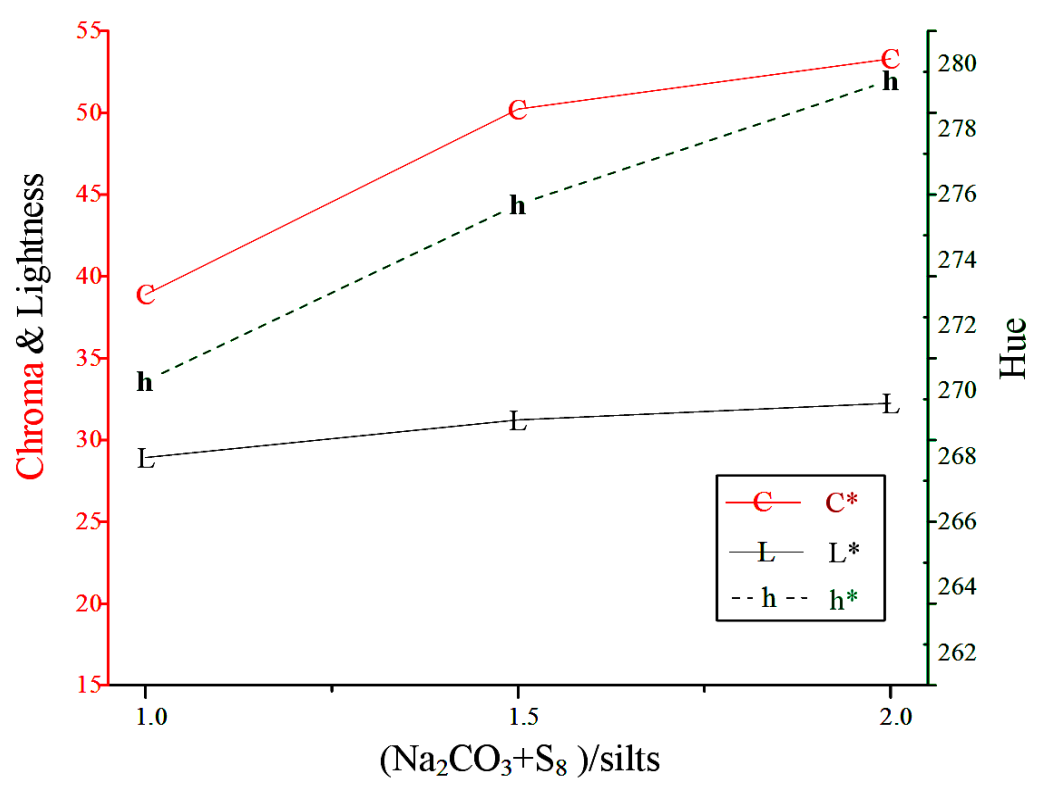

Figure 7. Effects of $\left(\mathrm{Na}_{2} \mathrm{CO}_{3}+\mathrm{S}_{8}\right)$ / silt mass ratio on the color properties of the products derived from $<5 \mu \mathrm{m}$ silts $\left(\mathrm{C} /\right.$ silts $\left.=0.2,800^{\circ} \mathrm{C}, 8 \mathrm{~h}\right)$.

\subsubsection{Active Carbon/Silts Ratio}

The effect of active carbon/silts ratio on the products color properties is shown in Table 5 and Figure 8. For active carbon/silts ratios $\leq 0.2$, with the increase of active carbon/silts ratio, the chroma and lightness were improved prominently from $44.5,45.3$ to 50.2 and $41.7,37.3$ to 31.2 , respectively. Increasing the ratio to 0.35 and 0.5 , the color properties deteriorated. The chroma decreased to 31.9 and 12.9, while the lightness became 29.5 and 46.3. The function of active carbon is to provide a reduced atmosphere in the reaction container to transform elemental sulfur to $\mathrm{S}_{2}{ }^{-}$. However, over-dosing of active carbon may deter the formation of $\mathrm{S}_{2}{ }^{-}$by its reaction with the sulfur to form carbonyl sulfide (COS). The oxidation stage, in which the yellow chromophore $\mathrm{S}_{2}{ }^{-}$is oxidized to the blue chromophore $\mathrm{S}_{3}{ }^{-}$, can also be influenced by carbon reacting with oxygen in the crucible to produce carbon monoxide [20]. The hue of the products of active carbon/silts ratio at 0.35 and 0.5 dropped to $258.9^{\circ}$ and $157^{\circ}$, inclining to a green $\left(180^{\circ}\right)$ tone, probably due to incomplete oxidation. Thus the proper active carbon/silts ratio is 0.2 . 
Table 5. Color properties of products derived from $<5 \mu \mathrm{m}$ silts at different active carbon/silts ratio $\left(800^{\circ} \mathrm{C}, 8 \mathrm{~h}\right)$.

\begin{tabular}{|c|c|c|c|c|c|}
\hline$\left(\mathrm{Na}_{2} \mathrm{CO}_{3}+\mathrm{S}_{8}\right) /$ Silts & C/Silts & $\mathrm{L}^{*}$ & $\mathrm{C}^{*}$ & $\mathbf{h}^{*}$ & Pantone \\
\hline 1.5 & 0 & 41.26 & 40.90 & 266.3 & \\
\hline 1.5 & 0.075 & 41.66 & 44.53 & 272.9 & \\
\hline 1.5 & 0.15 & 37.29 & 45.33 & 270 & \\
\hline 1.5 & 0.2 & 37.86 & 51.12 & 275.5 & \\
\hline 1.5 & 0.35 & 29.50 & 31.86 & 258.9 & \\
\hline 1.5 & 0.5 & 46.27 & 12.92 & 157 & \\
\hline
\end{tabular}

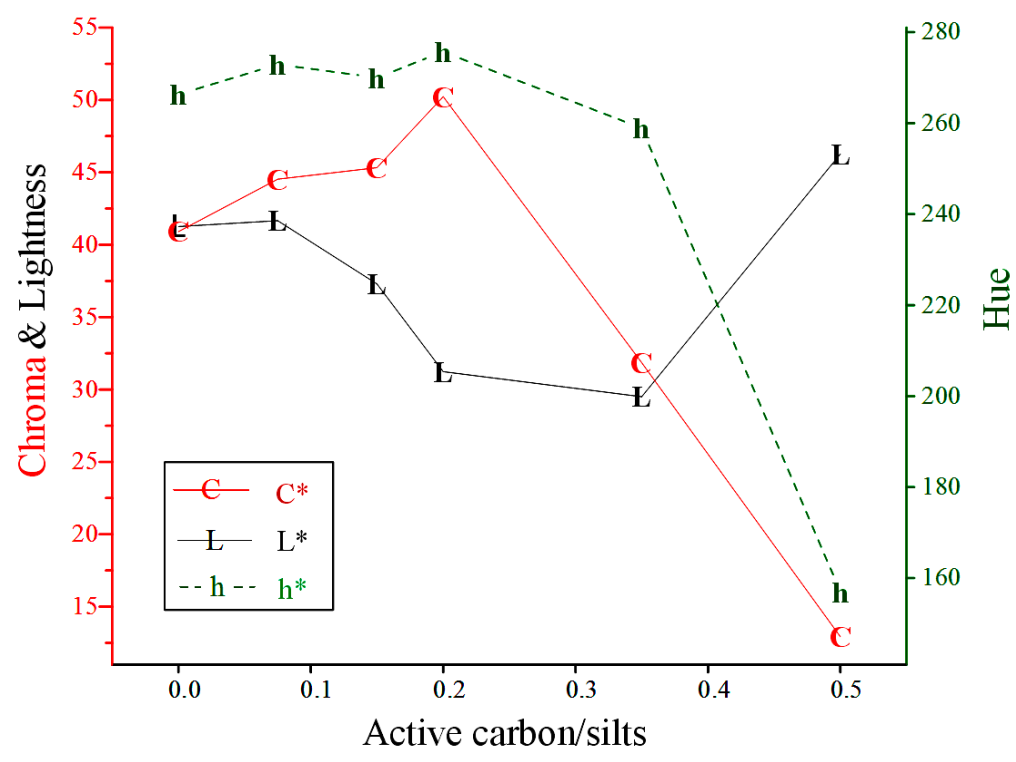

Figure 8. Effects of activated carbon/silt mass ratio on the color properties of the products derived from $<5 \mu \mathrm{m}$ silts $\left(\left(\mathrm{Na}_{2} \mathrm{CO}_{3}+\mathrm{S}_{8}\right) /\right.$ Silts $\left.=1.5,800{ }^{\circ} \mathrm{C}, 8 \mathrm{~h}\right)$.

\subsection{Effects of Mineral Composition of Starting Silts}

The results of Table 1 and Figure 4 show that as the silt sizes are fine, more clay minerals are contained in the silts. In this test, the raw and classified silts were used to investigate the effects of mineral composition on the ultramarine synthesis. The reactions were performed at $800{ }^{\circ} \mathrm{C}$ for $8 \mathrm{~h}$ with $\left(\mathrm{Na}_{2} \mathrm{CO}_{3}+\mathrm{S}_{8}\right) /$ silts ratio and the active carbon/silts ratio as 1.5 and 0.2 , respectively.

Figure 9 is the XRD patterns of the products synthesized from different silts. For raw $(\mathrm{Si} / \mathrm{Al}$ ratio $=2.77),<10 \mu \mathrm{m}(\mathrm{Si} / \mathrm{Al}$ ratio $=2.32)$ and $<5 \mu \mathrm{m}(\mathrm{Si} / \mathrm{Al}$ ratio $=1.95)$ silts, both lazurite and nepheline were formed, since the peak heights of lazurite are low, its amount may not be high. For $<2 \mu \mathrm{m}(\mathrm{Si} / \mathrm{Al}$ ratio $=1.58)$ silts, lazurite was the only phase and it was very distinct. Kowalak et al. [25] used different types of zeolite as aluminosilicate sources to synthesize ultramarine. Their results showed that the sodalite structure could be synthesized using zeolite $\mathrm{A}(\mathrm{Si} / \mathrm{Al}$ ratio $=1$ ) and zeolite $\mathrm{X}(\mathrm{Si} / \mathrm{Al}$ ratio $=1-1.5)$, while it could not using zeolite $\mathrm{Y}(\mathrm{Si} / \mathrm{Al}$ ratio $=1.5-3)$, mordenite $(\mathrm{Si} / \mathrm{Al}$ ratio $=5-10)$ and $\mathrm{ZSM}-5(\mathrm{Si} / \mathrm{Al}$ ratio $\geq 10)$. They concluded that the sodalite structure can be 
synthesized from aluminosilicate sources with small Si/Al ratios. Large $\mathrm{Si} / \mathrm{Al}$ ratios are unfavorable to the formation of sodalite phase and favor the formation of other undesired phases. From the results of Figure $9,<5 \mu \mathrm{m}$ silts seem to be on the margin between good and bad raw materials and agree with Kowalak et al.

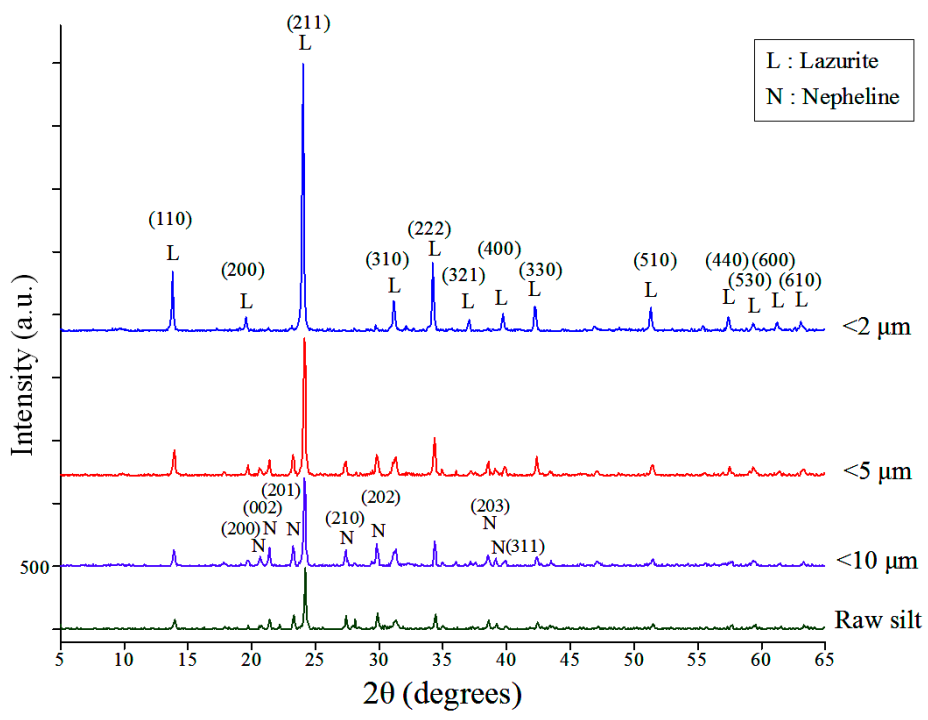

Figure 9. XRD patterns of the products derived from raw, $<10 \mu \mathrm{m},<5 \mu \mathrm{m}$ and $<2 \mu \mathrm{m}$ silts $\left(\left(\mathrm{Na}_{2} \mathrm{CO}_{3}+\mathrm{S}_{8}\right) /\right.$ silts $=1.5, \mathrm{C} /$ silts $\left.=0.2,800^{\circ} \mathrm{C}, 8 \mathrm{~h}\right)$.

The SEM images of the products are shown in Figure 10. According to Cork [19,20], the mean particle size of a commercial ultramarine should range from 0.7 to $5.0 \mu \mathrm{m}$. It is obvious that the products derived from the classified silts with particle size less than $5 \mu \mathrm{m}$ and so on meet the requirement.
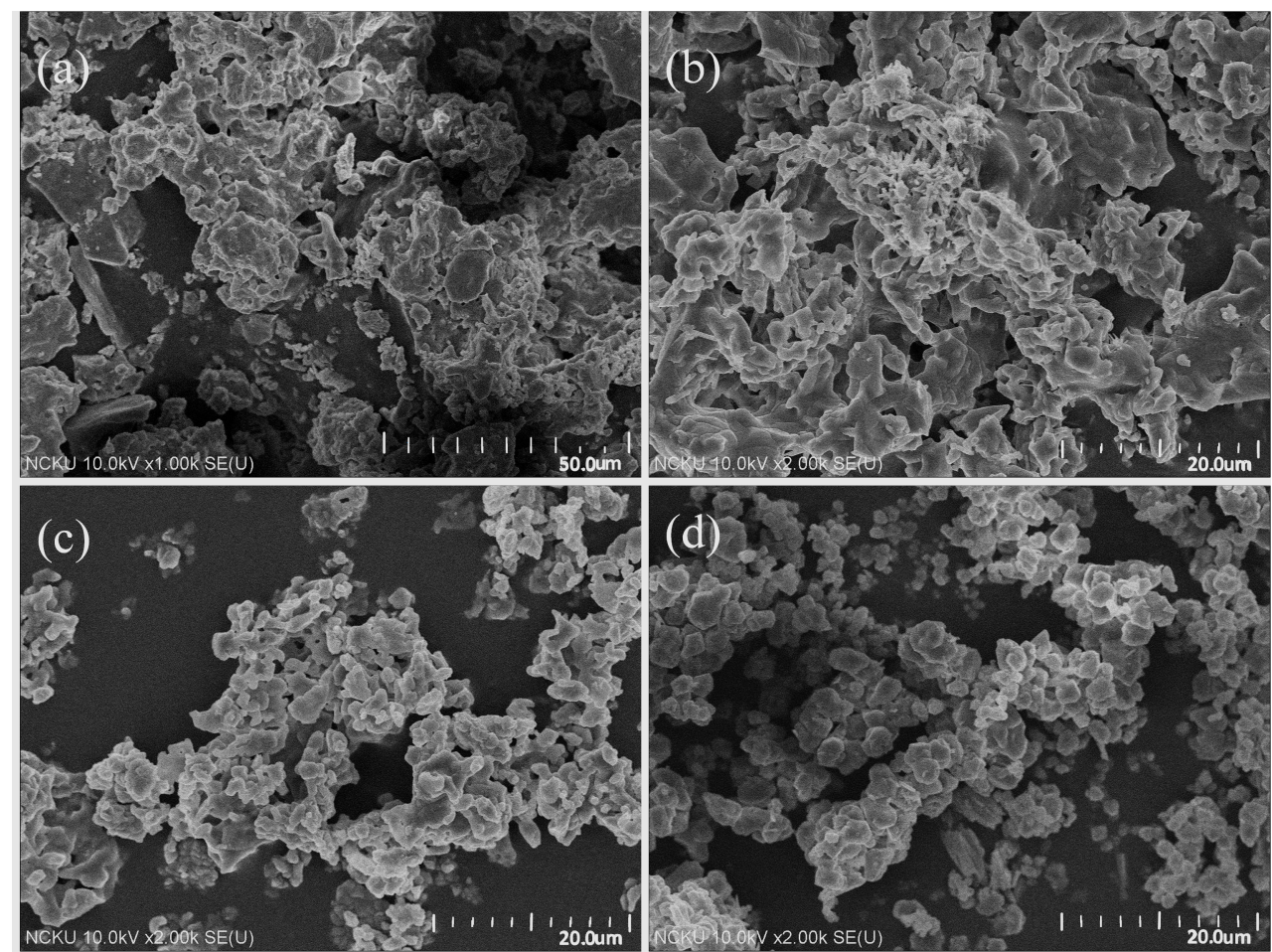

Figure 10. SEM micrographs of products derived from different silt samples:(a) raw; $(\mathbf{b})<10 \mu \mathrm{m}$; (c) $<5 \mu \mathrm{m}$ and $(\mathbf{d})<2 \mu \mathrm{m}$ silts $\left(\left(\mathrm{Na}_{2} \mathrm{CO}_{3}+\mathrm{S}_{8}\right) /\right.$ silts $=1.5, \mathrm{C} /$ silts $\left.=0.2,800{ }^{\circ} \mathrm{C}, 8 \mathrm{~h}\right)$. 
The color properties of the products from the four starting materials are listed in Table 6 . It shows that as the particle size becomes fine, the color properties make great progress, and when the particle size of the silts is $<5 \mu \mathrm{m}$, the chroma of the products can achieve over 50 with lightness below 40 and hue around $270^{\circ}$. From the results of Table 1 , the $\mathrm{Si} / \mathrm{Al}$ ratio of $<5 \mu \mathrm{m}$ silts is 1.95 , therefore either from the criterion of the sodalite phase formation or the color performance, a requirement of the silt size for the synthesis of ultramarine is passing $5 \mu \mathrm{m}$. In Table 6 , the color properties of additional three ultramarine samples, a commercial painting pigment (Sennelier l'Aquarelle), a natural lapis lazuli bead, and a recent report of ultramarine synthesized from kaolin clay [31], are also listed. It is obvious that the ultramarine of this study is competitive.

Table 6. Color performance of products derived from raw and classified silts $\left(\left(\mathrm{Na}_{2} \mathrm{CO}_{3}+\mathrm{S}_{8}\right) /\right.$ silts $=$ $1.5, \mathrm{C} /$ silts $=0.2,800^{\circ} \mathrm{C}, 8 \mathrm{~h}$ ) and three other natural and synthetic ultramarine samples.

\begin{tabular}{|c|c|c|c|c|}
\hline Particle Size & $\mathbf{L}^{*}$ & $C^{*}$ & $h^{*}$ & Pantone \\
\hline Raw & 30.19 & 22.40 & 253.3 & \\
\hline$<10 \mu \mathrm{m}$ & 34.68 & 35.94 & 266.4 & \\
\hline$<5 \mu \mathrm{m}$ & 37.86 & 51.12 & 275.5 & \\
\hline$<2 \mu \mathrm{m}$ & 38.48 & 52.38 & 271.2 & \\
\hline $\begin{array}{c}\text { Sennelier l'Aquarelle } \\
315 \text { serie } 2\end{array}$ & 24.04 & 61.52 & 299.6 & \\
\hline Lapis lazuli bead & 26 & 23.84 & 282.7 & \\
\hline $\begin{array}{l}\text { Ultramarine synthesized } \\
\text { from kaolin [31] }\end{array}$ & 33.7 & 53.7 & 290.1 & \\
\hline
\end{tabular}

\section{Conclusions}

This study provides a possibility to synthesize ultramarine blue from reservoir silts, thereby offering a new utilization of the silts. To remove the unusable quartz and keep the useful clays, so as to decrease the $\mathrm{Si} / \mathrm{Al}$ ratio of the silts to less than 2, the raw silts must be classified to obtain the fine part. In this study the particle sizes must be smaller than $5 \mu \mathrm{m}$. Ultramarine can be synthesized with the conditions: $\mathrm{Na}_{2} \mathrm{CO}_{3} / \mathrm{S}_{8}$ wt. ratio $=1 ;\left(\mathrm{Na}_{2} \mathrm{CO}_{3}+\mathrm{S}_{8}\right) /$ silts ratio of 1.5 ; active carbon/silts ratio of 0.2 and calcination at $800{ }^{\circ} \mathrm{C}$ for $8 \mathrm{~h}$. Under the optimal conditions, the ultramarine synthesized from $<2 \mu \mathrm{m}$ silts has the following color properties: chroma 52.4; lightness 38.5 and hue $271.2^{\circ}$.

Acknowledgments: The Administration Bureau of Nan-Hua Reservoir is greatly appreciated for the supply of the silt samples.

Author Contributions: Dah-Tong Ray conceived and designed the experiments; Yin-Hsiu Hsiao performed the experiments; Yun-Hwei Shen analyzed the data; Yin-Hsiu Hsiao and Dah-Tong Ray wrote the paper.

Conflicts of Interest: The authors declare no conflict of interest.

\section{References}

1. Chaudhry, M.A.; Rehman, H.-U. Worldwide experience of sediment flushing through reservoirs. MURJET 2012, 31, 395-408. 
2. International Commission on Large Dams Introduction. Sedimentation and Sustainable Use of Reservoirs and River Systems; Stellenbosch University: Stellenbosch, South Africa, 2009; pp. 17-19.

3. Sinotech Engineering Consultants LTD. The aquatic environment in Taiwan. In The Climate Change Knowledge Database and Data Integration Platform (4/4); Water Resources Agency, Ministry of Economic Affairs: Taipai, Taiwan, ROC, 2013; pp. 2-8.

4. Wu, M.L. The Study on the Clay of Reservoir in Taiwan. Master's Thesis, NCKU, Tainan, Taiwan, 2009.

5. Kendrick, E.; Dann, S.E.; Hellgardt, K.; Weller, M.T. The effect of differents precursors on the synthesis of ultramarine blue using a modified test furnace. Stud. Surf. Sci. Catal. 2004, 154, 3059-3066.

6. Hassan, I.; Peterson, R.C.; Grundy, H.D. The structure of lazurite, ideally $\mathrm{Na}_{6} \mathrm{Ca}_{2}\left(\mathrm{Al}_{6} \mathrm{Si}_{6} \mathrm{O}_{24}\right) \mathrm{S}_{2}$, a member of the sodalite group. Acta Cryst. 1985, C41, 827-832.

7. Climent-Pascual, E.; Sáez-Puche, R.; Gómez-Herrero, A.; Romero de Paz, J. Cluster ordering in synthetic ultramarine pigments. Microporous Mesoporous Mater. 2008, 116, 344-351. [CrossRef]

8. Prener, J.S.; Ward, R. The preparation of ultramarines. J. Am. Chem. Soc. 1950, 72, 2780-2781. [CrossRef]

9. Tarling, S.E.; Barnes, P. The structure and Si, Al distribution of the ultramarines. Acta Cryst. 1988, B44, 128-135. [CrossRef]

10. Reinen, D.; Lindner, G.-G. The nature of the chalcogen colour centres in ultramarine-type solids. Chem. Soc. Rev. 1999, 28, 75-84. [CrossRef]

11. Fabian, J.; Komiha, N.; Linguerri, R.; Rosmus, P. The absorption wavelengths of sulfur chromophors of ultramarines calculated by time-dependent density functional theory. J. Mol. Struc. Theochem 2006, 801, 63-69. [CrossRef]

12. Clark, R.J.H.; Cobbold, D.G. Characterization of sulfur radical anions in solutions of alkali polysulfides in dimethylformamide and hexamethylphosphoramide and in the solid state in ultramarine blue, green, and red. Inorg. Chem. 1978, 17, 3169-3174. [CrossRef]

13. Goslar, J.; Lijewski, S.; Hoffmann, S.K.; Jankowska, A.; Kowalak, S. Structure and dynamics of $\mathrm{S}_{3}{ }^{-}$radicals in ultramarine-type pigment based on zeolite A: Electron spin resonance and electron spin echo studies. J. Chem. Phys. 2009, 130, 204504. [CrossRef] [PubMed]

14. Heinemann, C.; Koch, W.; Lindner, G.-G.; Reinen, D. Electronic spectrum of $\mathrm{S}_{2}{ }^{-}$, the electron affinity of $\mathrm{S}_{2}$, and the binding energies of neutral and anionic $S_{3}$ clusters. Phys. Rev. 1995, 52, 1024. [CrossRef]

15. Cotton, F.A.; Harmon, J.B.; Hedges, R.M. Calculation of the ground state electronic structures and electronic spectra of di-and trisulfide radical anions by the scattered wave-SCF-X $\alpha$ method. J. Am. Chem. Soc. 1976, 98, 1417-1424. [CrossRef]

16. Orna, M.V. Colorant usage from antiquity to the Perkin Era. In The Chemical History of Color; Springer: Heidelberg/Berlin, Germany, 2013; pp. 47-78.

17. Chivers, T. Ubiquitous trisulfur radical ion $\mathrm{S}_{3}{ }^{-}$. Nature 1974, 252, 32-33. [CrossRef]

18. Chivers, T.; Elder, P.J.W. Ubiquitous trisulfur radical anion: Fundamentals and applications in materials science, electrochemistry, analytical chemistry and geochemistry. Chem. Soc. Rev. 2013, 42, 5996-6005. [CrossRef] [PubMed]

19. Cork, W.B. Ultramarine pigments. In Pigments, Inorganic; Wiley-VCH: Weinheim, Germany, 1993; pp. 87-92.

20. Landman, A.A.; De Waal, D. Fly ash as a potential starting reagent for the synthesis of ultramarine blue. Mater. Res. Bull. 2004, 39, 655-667. [CrossRef]

21. Gobeltz, N.; Demortier, A.; Lelieur, J.P.; Duhayon, C. Encapsulation of the chromophores into the sodalite structure during the synthesis of the blue ultramarine pigment. J. Chem. Soc. Faraday Trans. 1998, 94, 2257-2260. [CrossRef]

22. Arieli, D.; Vaughan, D.E.W.; Goldfarb, D. New Synthesis and insight into the structure of blue ultramarine pigments. J. Am. Chem. Soc. 2004, 126, 5776-5788. [CrossRef] [PubMed]

23. Kumins, C.A.; Tuckahoe, N.Y. Process for Making Ultramarine. U.S. Patent 2544694, 13 March 1951.

24. Lelieur, J.-P.V.; Duhayon, C.L.; Hautecoeur, N.S.; Demortier, A.M.; Lede, B.J.; Coopman, P.J.; Leghie, P. Ultramarine Pigment Synthesis Process. U.S. Patent 7632347 B2, 15 December 2009.

25. Kowalak, S.; Pawłowska, M.; Miluśka, M.; Stróżyk, M.; Kania, J.; Przystajko, W. Synthesis of ultramarine from synthetic molecular sieves. Coll. Surf. A Physicochem. Eng. Asp. 1995, 101, 179-185. [CrossRef]

26. Kowalak, S.; Jankowska, A.; Łączkowska, S. Preparation of various color ultramarine from zeolite A under environment-friendly conditions. Catal. Today 2004, 90, 167-172. [CrossRef] 
27. Kowalak, S.; Jankowska, A.; Zeidler, S. Ultramarine analogs synthesized from cancrinite. Microporous Mesoporous Mater. 2006, 93, 111-118. [CrossRef]

28. Chen, K.T.; Ray, D.T. A study on the synthesis of zeolites and ultramarine pigment from reservoir sediments. Taiwan Min. Ind. 2013, 65, 19-27.

29. De Menezes, R.A.; Da Paz, S.P.A.; Angélica, R.S.; De Freitas Neves, R.; Castella Pergher, S.B. Color and shade parameters of ultramarine zeolitic pigments synthesized from kaolin waste. Mater. Res. 2014, 17, $23-27$. [CrossRef]

30. Gobeltz, N.; Demortier, A.; Lelieur, J.P. Identification of the products of the reaction between sulfur and sodium carbonate. Inorg. Chem. 1998, 37, 136-138. [CrossRef] [PubMed]

31. Sancho, J.P.; Restrepo, O.J.; Garcia, P.; Ayala, J.; Fernandez, B.; Verdeja, L.F. Ultramarine blue from Asturian "hard" kaolins. Appl. Clay Sci. 2008, 41, 133-142. [CrossRef]

(C) 2017 by the authors. Licensee MDPI, Basel, Switzerland. This article is an open access article distributed under the terms and conditions of the Creative Commons Attribution (CC BY) license (http:/ / creativecommons.org/licenses/by/4.0/). 